\title{
Strength Properties of Concrete Specimens with Metakaolin and Methylcellulose
}

\author{
Merin Clara Mathan ${ }^{1}$, Cinaya Tony ${ }^{2}$ \\ ${ }^{1}$ PG Scholar, Structural Engineering, SBCE \\ ${ }^{2}$ Assistant Professor, Department of Civil Engineering, SBCE
}

\begin{abstract}
Concrete is the most commonly used material for construction. Production of cement results in a lot of environmental pollution as it involves the emission of $\mathrm{CO}_{2}$ gas. Supplementary cementatious materials including silica fumes, fly ash, slag, Rice Husk Ash and Metakaolin have been used in recent years as cement replacement material for developing HSC with improved workability, strength and durability with reduced permeability. Metakaolin is a dehydroxylated aluminium silicate. It is an amorphous non crystallized material, constituted of lamellar particles. From the recent research works using Metakaolin, it is evident that it is a very effective pozzolanic material and it effectively enhances the strength parameters of concrete. Reducing sulphate attack and improving air-void network. Methylcellulose(MC)will be the one of the bonding strength increasing material used to increase the strength of the concrete along with the metakaolin. In this thesis paper, studies on partial replacement of cement with metakaolin as different percentage in $\mathrm{M30}$ mix. The replacement levels were 10\%, 15\%, 20\%, 25\%, upto 30\% (by weight) for Metakaolin. The result obtained from the test is compared with normal specimens without replacement. At some percentage there will be the decrease in strength. At some percentage there will be the decrease in strength.To increases the strength in that percentage MC will be added and compare with the control specimen.
\end{abstract}

Keywords: Admixture, High Strength Concrete (HSC), Metakaolin.

\section{Introduction}

Concrete is generally classified as Normal Strength Concrete (NSC), High Strength Concrete (HSC) and Ultra High Strength Concrete (UHSC). HSC differs from ordinary concrete with respect to its performance in fresh and hardened states that are mainly driven by exceptional material components and mixture proportions. It incorporates several special ingredients such as high-range water reducer (HRWR), supplementary cementing material (SCM), in addition to the basic materials used for ordinary concrete. Pozzolanic materials including silica fumes, fly ash, slag, Rice Husk Ash and Metakaolin have been used in recent years as cement replacement material for developing HSC with improved workability, strength and durability with reduced permeability. Metakaolin, which is a relatively new material in the concrete industry is effective in increasing strength, reducing sulphate attack and improving air-void network. But at some percentage of replacement of cement with metakaolin there will be a decrease in strength. To rectify this major problem ,Methylcellulose(MC) will be used to increases the strength of the concrete specimen. The use of MC as an admixture in cement paste or concrete was found to increases the bond strength between the concrete and reinforcement .The bond strength increased with increasing the MC amount. The bond of concrete to steel reinforcing bars and other reinforcements is important, since concrete is usually reinforced and the reinforcement often tends to carry the load. The bond strength between concrete and reinforcement depends much on the concrete mix design, although it also depends on the reinforcement surface condition. By reducing the cement content in the concrete the production of cement will also reduce, Which reduces the harmful emissions of greenhouse gases. So it is considered as ecofriendly.
According to various literature reviews, it is observed that there is a problem related to decreasing the strength at certain percentage of replacement of metakaolin. So this paper is an attempt to study the strength properties along with the metakaolin and methylcellulose.

\section{Literature Survey}

[1] J. M. Khatib, O. Kayali and R. Siddique (2009)

Cement was partially replaced with $0 \%, 20 \%, 40 \%$ and $60 \%$ FA, respectively, and 5\% MK cement was partially replaced (by mass)with $0 \%, 20 \%, 40 \%$, and $60 \%$ FA, respectively, and $10 \% \mathrm{MK}$ The water to binder $(\mathrm{w} / \mathrm{b})$ ratio for all mixes was maintained constant at 0.5 . For each mix nine prisms of dimensions $40 \mathrm{~mm} \times 40 \mathrm{~mm} \times 160 \mathrm{~mm}$ and 18 cubes of 50 $\mathrm{mm}$ side length were prepared. Replacing $5 \%$ and $10 \%$ of the binder with MK without the use of FA causes an increase in strength at almost all curing ages .

[2] B. B. Patil1, P. D. Kumbhar (2012)

After 28 days curing period, specimens were tested under a compression testing machine of $2000 \mathrm{KN}$ capacity .Durability test was carried out by $3.5 \% \mathrm{NaCl}$ and $5 \%$ $\mathrm{MgSO}_{4}$ solution for a period of 180 days. Addition of high reactivity metakaolin results an increase in the strength. High reactivity metakaolin rapidly removes calcium hydroxide from the system and accelerates the ordinary Portland cement (OPC) hydration.

\section{[3]Sanjay N. Patil, Anil K. Gupta, Subhash S. Deshpande} (2011)

HRM reacting aggressively with calcium hydroxide which results in significant performance of concrete. 5\%, 10\% and $15 \%$ of cement content is replaced by HRM or silica fume for comparative study. $150 \mathrm{~mm}$ cube specimens for compressive strength test and $100 \times 100 \times 400 \mathrm{~mm}$ prism specimens for flexure test. HRM had a better workability, 


\section{International Journal of Science and Research (IJSR) \\ ISSN (Online): 2319-7064}

Index Copernicus Value (2013): 6.14 | Impact Factor (2015): 6.391

compared to control specimen and concrete containing silica fume.

[4]A. Bonakdar, M. Bakhshi, and M. Ghalibafian(2013) High Reactivity Metakaolin (HRM) is an engineered pozzolanic mineral admixture, reacting aggressively with calcium hydroxide which results in significant performance of concrete. HRM has been introduced to be a beneficial alternative for silica fume, required in the formulation of high strength/performance concrete. In this study, different aspects of concrete mechanical behaviors have been studied including compressive, flexural and splitting tensile strengths. Also some characteristics of concrete durability were investigated including water absorption, water penetration and gas permeability. In mixture proportioning, $5 \%, 10 \%, 15 \%, 20 \%, 25 \%, 30 \%$ of cement content is replaced by HRM or silica fume for comparative study. It was observed that both concrete with HRM and silica fume.

\section{Objective of the Work}

The objective is to find out the strength properties of concrete specimens by adding methylcellulose along with the metakaolin.

\section{Methodology}

The methodology of the work consist of

1) Selection of grade of concrete; M30.

2) Mix design of M30 grade concrete.

3) Preparation of Test Specimen (Replaced 0,10,15,20, 25,30 and $35 \%$ of MK with cement)

4) Finding the Optimum Percentage of Replacement.

5) Preparation of Test Specimen (Adding 0.4, 0.6 and $0.8 \%$ of methylcellulose).

6) Discussion of Result.

\section{Material Test}

Table 1: Material Testing Results

\begin{tabular}{|c|c|c|c|}
\hline \multicolumn{1}{|c|}{ Test } & Material & Equipment Used & $\begin{array}{c}\text { Values } \\
\text { Obtained }\end{array}$ \\
\hline Specific Gravity & $\begin{array}{c}\text { Ramco cement } \\
\text { (OPC 43 grade) }\end{array}$ & Le Chatelier flask & 3.2 \\
\hline Specific Gravity & Fine Aggregates & pycnometer & 2.61 \\
\hline Specific Gravity & $\begin{array}{c}\text { Coarse } \\
\text { Aggregates }\end{array}$ & Wire basket & 2.77 \\
\hline Water absorption & Fine Aggregates & Vessel & $1.02 \%$ \\
\hline Water absorption & $\begin{array}{c}\text { Coarse } \\
\text { Aggregates }\end{array}$ & vessel & $0.6 \%$ \\
\hline Specific Gravity & Metakaolin & Le Chatelier flask & 2.9 \\
\hline workability & M30 concrete & Slump cone & $110 \mathrm{~mm}$ \\
\hline
\end{tabular}

\section{Mix Design}

Table 2: M30 Mix Proportioning

\begin{tabular}{|c|c|}
\hline Cement $(\mathrm{Kg} / \mathrm{m} 3)$ & 438 \\
\hline Fine aggregate $(\mathrm{Kg} / \mathrm{m} 3)$ & 695 \\
\hline Coarse aggregate $(\mathrm{Kg} / \mathrm{m} 3)$ & 1107 \\
\hline Water $(\mathrm{Li} / \mathrm{m} 3)$ & 197 \\
\hline Water cement ratio & 0.45 \\
\hline \multicolumn{2}{|c|}{ Mix ratio $1: 1.59: 2.52: 0.45$} \\
\hline
\end{tabular}

\section{Experimental Investigation}

\section{A. Experimental Program}

The test program consists of casting and testing beams in the size $100 \times 100 \times 500 \mathrm{~mm}$, cubes in the size of $150 \times 150$ $\mathrm{x} 150 \mathrm{~mm}$ and cylinder in the size of $150 \mathrm{~mm}$ diameter and $300 \mathrm{~mm}$ height. In this experiment three beams out of which one beam is reinforced and other two are unreinforced, six cubes and three cylinders were casted for each percentage of replacement of metakaolin including control specimens. The specimens are casted are control specimens(CS), $10 \%$ replacement of cement (M1),15\% replacement of cement (M2), 20\% replacement of cement(M3), 25\% replacement of cement(M4), and 30\% replacement of cement(M5).And to find out the compressive strength ,flexure strength, split tensile strength and modulus of elasticity of the specimens. Casting process is performed according to the basic standards and concrete treatment process is performed for 28 day. After the result analysis, at some percentage of replacement there will be a decrease in the strength when compared to the target strength of M30 mix. At that percentage various amount of methylcellulose may added in the reinforced beam of size $70 \times 20 \times 20 \mathrm{~cm}$ and to find out the strength of the beam by using the loading frame .

\section{Experimental Results and discussion}

\subsection{Compressive strength}

The compressive strength values varied from 26.20 to 28.50 $\mathrm{N} / \mathrm{mm}^{2}$ for 7 days strength. Also, it varied from 38.50 to $39.50 \mathrm{~N} / \mathrm{mm}^{2}$ for 28 days. It was found that, there was much variation in the compressive strength of conventional concrete and replaced specimens.It shown that there will be increase in strength and at $35 \%$ replacement there will be sudden decrease in the strength.

Table 3:Compressive strength of specimens

\begin{tabular}{|c|c|c|c|}
\hline $\begin{array}{l}\text { Sl } \\
\text { No }\end{array}$ & $\begin{array}{c}\% \\
\text { of metakaolin }\end{array}$ & $\begin{array}{c}7 \text { days } \\
\text { Compressive } \\
\text { strength }\left(\mathrm{N} / \mathrm{mm}^{2}\right)\end{array}$ & $\begin{array}{c}28 \text { days } \\
\text { compressive } \\
\text { strength }\left(\mathrm{N} / \mathrm{mm}^{2}\right)\end{array}$ \\
\hline 1 & 10 & 26.20 & 38.50 \\
\hline 2 & 15 & 32.00 & 46.29 \\
\hline 3 & 20 & 38.10 & 58.59 \\
\hline 4 & 25 & 32.03 & 50.52 \\
\hline 5 & 30 & 28.50 & 39.15 \\
\hline 6 & 35 & 26.32 & 37.89 \\
\hline
\end{tabular}

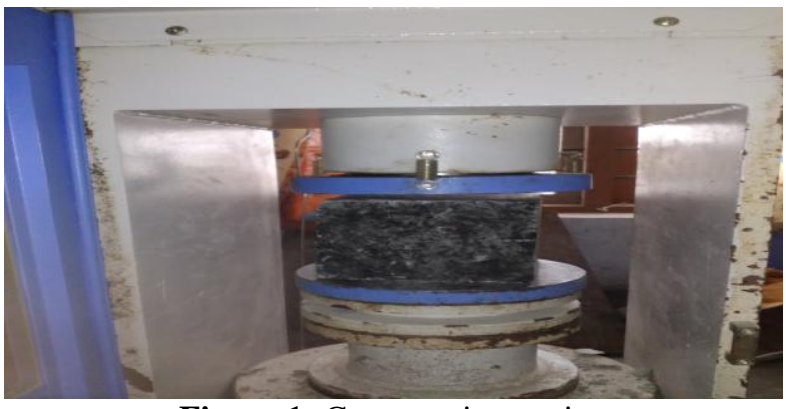

Figure 1: Compression testing 


\section{International Journal of Science and Research (IJSR) \\ ISSN (Online): 2319-7064}

Index Copernicus Value (2013): 6.14 | Impact Factor (2015): 6.391

\subsection{Spliting Tensile Strength}

The splitting tensile strength values varied from $3.4 \mathrm{~N} / \mathrm{mm}^{2}$ to $3.0 \mathrm{~N} / \mathrm{mm}^{2}$ at 28 days, from this result, the amount of metakaolin is increases the split tensile strength will be decreases.From this result,the split tensile strength will be more in $20 \%$ replacement level.

Table 4: Split tensile strength of specimens

\begin{tabular}{|c|c|c|}
\hline Sl. No & \% of metakaolin & 28days Split tensile strength $\left(\mathrm{N} / \mathrm{mm}^{2}\right)$ \\
\hline 1 & 10 & 3.4 \\
\hline 2 & 15 & 2.9 \\
\hline 3 & 20 & 3.7 \\
\hline 4 & 25 & 3.2 \\
\hline 5 & 30 & 3.0 \\
\hline 6 & 35 & 2.8 \\
\hline
\end{tabular}

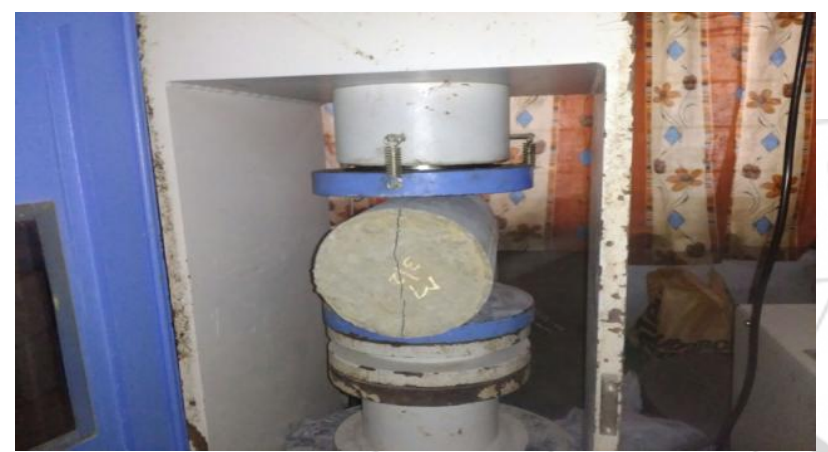

Figure 2: Split tensile test

\subsection{Flexural strength}

The flexural strength results were found in the range of 4.34 $\mathrm{N} / \mathrm{mm}^{2}$ to $4.16 \mathrm{~N} / \mathrm{mm}^{2}$ for 28 days. From the results, it was observed that, replaced specimens can produce strength results.

Table 5: Flexural strength of the specimens

\begin{tabular}{|c|c|c|}
\hline Sl. No & \% of metakaolin & 28days Flexural strength $\left(\mathrm{N} / \mathrm{mm}^{2}\right)$ \\
\hline 1 & 10 & 4.34 \\
\hline 2 & 15 & 4.8 \\
\hline 3 & 20 & 5.16 \\
\hline 4 & 25 & 4.36 \\
\hline 5 & 30 & 4.16 \\
\hline 6 & 35 & 3.98 \\
\hline
\end{tabular}

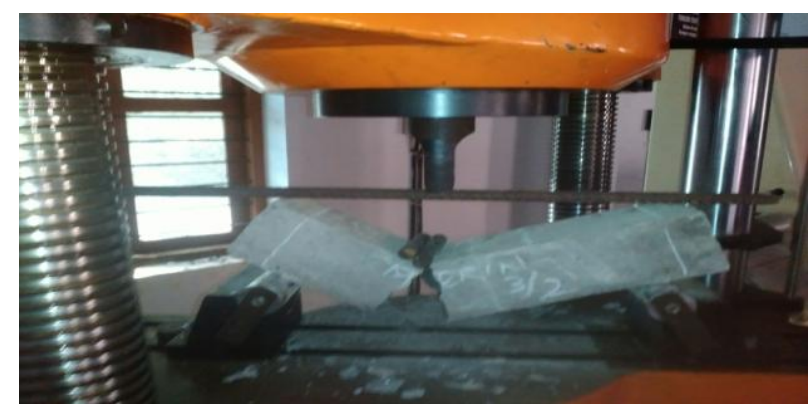

Figure 3: Flexural Testing arrangement

\subsection{Modulus of elasticity}

The young's modulus may be vary from $30.90 \mathrm{GPa}$ to 34.4GPa.The amount of metakaolin will be increases the young's modulus may be decreases.From the result, there will be small variation in the young's modulus.

Table 6: Modulus of elasticity of the specimens

\begin{tabular}{|c|c|c|}
\hline Sl. No & \% of metakaolin & Young's Modulus $(\mathrm{GPa})$ \\
\hline 1 & 10 & 30.90 \\
\hline 2 & 15 & 34.01 \\
\hline 3 & 20 & 38.27 \\
\hline 4 & 25 & 35.53 \\
\hline 5 & 30 & 34.4 \\
\hline 6 & 35 & 32.45 \\
\hline
\end{tabular}

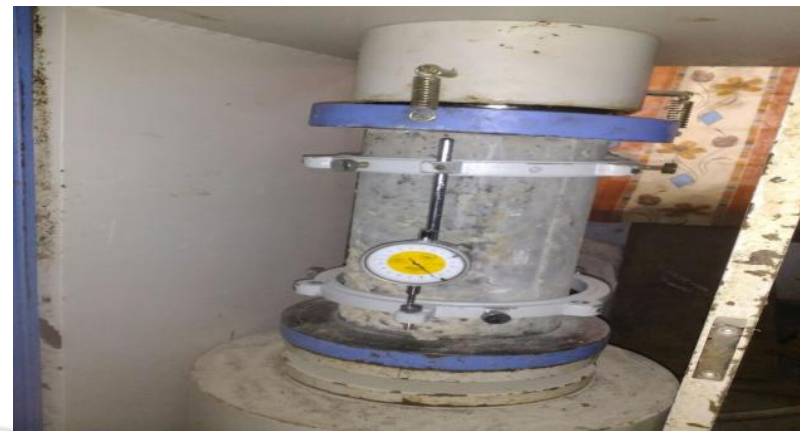

Figure 4: Modulus of elasticity

\subsection{Strength by adding methylcellulose}

By observing the results, at $35 \%$ replacement of cement by metakaolin.There will be decrease in the strength when compared with the target strength of M30 mix. $0.2 \%, 0.4 \%, 0.6 \%$ and $0.8 \%$ (by weight of cement) of methylcellulose is adding into the $35 \%$ replacement beam specimen the strength will be given below. The load will be vary from $130 \mathrm{KN}$ to $186 \mathrm{KN}$. The load will be increases with increase in the amount of methylcellulose with $35 \%$ replacement of cement by metakaolin. The maximum load will be:

Table 7: Maximum load of the specimen

\begin{tabular}{|c|c|c|}
\hline Sl no & \% of MC & Maximum load $(\mathrm{KN})$ \\
\hline 1 & 0 & 130 \\
\hline 2 & 0.2 & 150 \\
\hline 3 & 0.4 & 169 \\
\hline 4 & 0.6 & 175 \\
\hline 5 & 0.8 & 186 \\
\hline
\end{tabular}

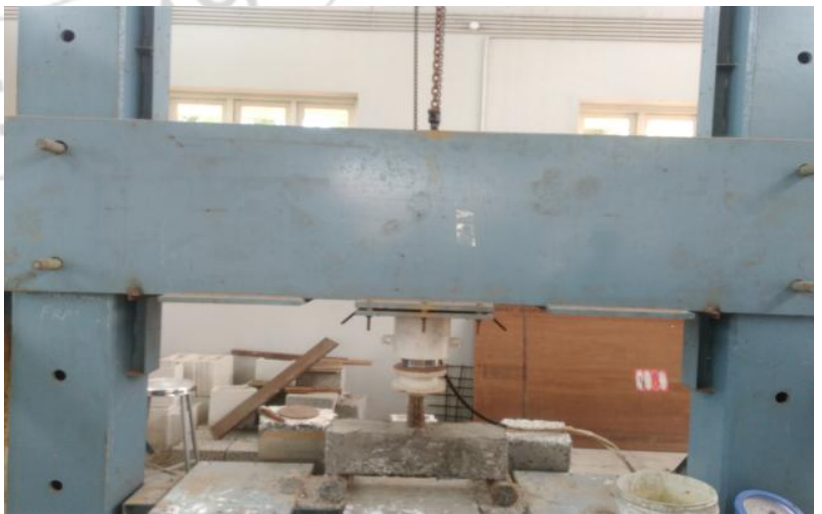

Figure 5: Loading frame arrangement

\section{Conclusions}

By compairing with normal specimens with replacement specimens it shows that it will have more strength. So we use metakaolin as a replacement material for cement.If we use this, the strength will be increases and amount of cement will be low. which reduces the emission of carbon dioxide 
during the production of cement. The compressive strength of concrete cubes made with metakaolin were found to be greater strength than the normal specimens .It was also found that the flexural strength and splitting tensile strength results were similar to that of compression strength test results.The strength will be increases with the increases in the amount of methylcellulose.

\section{Scope of Future Study}

From the comparative study,there will be a decrease in the strength at $35 \%$ replacement of metakaolin,when compare with M30 mix.To attain the target strength of M30 mix at $35 \%$ replacement of specimen. Another bonding strength increasing material is help to attain the strength of M30 mix at $35 \%$ replacement level. And also to find the optimum percentage of $\mathrm{MC}$ along with the metakaolin.

\section{References}

[1] "Strength and Durability Properties of High Performance Concrete incorporating High Reactivity Metakaolin" by B.B. Patil and P.D. Kumbhar.

[2] "Shrinkage of Polypropylene Fiber-Reinforced HighPerformance Concrete" by Drago Saje and Branko Bandelj

[3] "Metakaolin Pozzolanic Material For Cement in High Strength Concrete" by Sanjay N. Patil ,Anil K. Gupta and Subhash S. Deshpande

[4] Dinakar P. High reactive metakaolin for high strength and high performance concrete. The Indian Concrete Journal, April 2011, 28-32.

[5] Khatib, J. M., and Clay, R. M. 2004. "Absorption characteristics of metakaolin concrete." Cem. Concr. Res., 341, 19-29.

[6] Gleize, P. J. P., Cyr, M., and Escadeillas, G. 2007. "Effects of metakaolin on autogenous shrinkage of cement pastes." Cem. Concr. Compos., 29, 80-87

\section{Author Profile}

Merin Clara Mathan is MTech student, Structural Engineering, Sree Buddha College of Engineering. University of Kerala. She did Bachelor of Engineering in civil engineering from Anna University Chennai.

Cinaya Tony is Assistant Professor, Department of Civil Engineering, Sree Buddha College of Engineering, She has done Master of Technology in Fluid mechanics from College of engineering, Trivandrum and B. Tech in Civil Engineering from SCMS school of Engineering and technology. 